\title{
NOTES.
}

The April number (volume 13, number 2) of the Transactions of the American Mathematical Society contains the following papers: "A generalization of Weierstrass's preparation theorem for a power series in several variables," by G. A. BLIss; "An existence theorem for periodic solutions," by W. D. MacMrllaN; "A condition that a function in a projective space be rational," by W. F. OsGooD; "A method of proving certain theorems relating to rational functions which are adjoint to an algebraic equation for a given value of the independent variable," by J. C. FieLDs: "The dependence of focal points upon curvature for problems of the calculus of variations in space," by M. B. WhITE; "Orthocentric properties of the plane directed $n$-line," by J.E. HodGson; "Certain singularities of point transformations in space of three dimensions," by S. E. URNER; "Multiple correspondences determined by the rational plane quintic curve," by J. R. ConNer.

The April number (volume 34, number 2) of the American Journal of Mathematics contains: "The groups of birational transformations of algebraic curves of genus 5," by J. V. McKelvey; "The general theory of linear $q$-difference equations," by R. D. Carmichael; "Concerning linear projective order," by A. R. Schweitzer; "On certain expansions of elliptic, hyperelliptic, and related periodic functions," by $\mathrm{F}$. R. Moulton; "On cubic birational space transformations," by H. P. Hudson; "On the definition of multiplication of irrational numbers," by Oswald Veblen.

THe Library of Congress will have ready for distribution in July the first of a series of catalogue cards forming the beginning of a dictionary catalogue of all articles in the Encyklopädie der mathematischen Wissenschaften and the Encyclopédie des Sciences mathématiques. The material for all parts of the two Encyclopedias thus far issued has already been supplied by Brown University, which will continue to supply the material as future parts appear.

AT the meeting of the London mathematical society held on March 14 the following paper was read: By G. T. BENNETT, "The cubic surface as a degenerate quartic." 
The date of the Fifth international congress of mathematicians at Cambridge, England, is August 22-28. Series of lectures are announced by F. Borel, E. W. Brown, A. Kneser, E. G. H. Landau, J. Larmor, and Sir W. White. The American members of the organizing committee are Professors M. Bôcher, J. C. Fields, E. H. Moore, F. R. Moulton, B. O. Peirce, J. Pierpont, and A. G. Webster. Requests for information regarding the congress should be addressed to the general secretary of the organizing committee, Professor E. W. Hobson, Christ's College, Cambridge.

THe academy of sciences of Paris announces that the grand prize (3000 frs.) will be awarded in 1914 for the solution of the following problem. "To perfect the theory of functions of one variable which can be represented by trigonometric series of several arguments which are linear functions of the variable. The academy will be pleased to consider important applications to mathematical physics and to celestial mechanics." The following problem is proposed for the Fourneyron prize (1000 frs.) in 1914. "Theoretical and experimental study of turbines."

The royal academy of sciences of Belgium proposes the following prize problems for 1913: "An important contribution to the infinitesimal geometry of curved surfaces" (800 frs.). "Summarize the theory of systems of space cubic curves and make a new contribution to the theory" (800 frs.). Competing memoirs should be sent to the secretary before August 1, 1913.

THE first congress of Russian mathematicians, including university professors and teachers in the secondary schools was held at St. Petersburg, January 6-16, 1912, in which more than 1200 persons participated. The president of the congress, Professor A. VAssilief, delivered an able address "On instruction in mathematics and philosophy in the secondary schools." Extracts of the papers will appear in an early number of Enseignement Mathématique.

THE following university courses in mathematics are offered during the summer semester of 1912 .

University of Berlin. - By Professor H. A. Schwarz: 
Space curves and surfaces, four hours; Analytic functions, four hours; Hypergeometric series, two hours; Colloquium, two hours; Seminar, two hours. - By Professor G. Frobenius: Determinants, four hours; Seminar, two hours. - By Professor F. Sсноттку: Quadric surfaces, four hours; Riemann's theory, four hours; Seminar, two hours. - By Professor R. LehmanNFilhés: Mechanics, four hours; with exercises, one hour. By Professor G. Hettner: Introduction to ordinary differential equations, two hours. - By Professor J. KNoBladch: Applications of elliptic functions, four hours; Integral calculus, four hours; Selected chapters of analytic geometry, one hour. - By Professor I. ScHUR: Elliptic functions, four hours; Differential calculus, four hours; with exercises, one hour.

University of Bonn. - By Professor E. Study: Differential and integral calculus, four hours; with exercises, one hour; Quaternions, two hours; Seminar, two hours. - By Professor F. London: Descriptive geometry, four hours; Analytic geometry, II, three hours; with exercises, one hour. - By Dr. J. O. MÜLLER: Theory of numbers, three hours.

University of Göttingen.-By Professor F. Klein: Analytic geometry, four hours; Seminar, two hours.-By Professor D. Hilbert: Ordinary differential equations, four hours; Mathematical foundation of physics, four hours.By Professor C. Runge: Mechanics, II, six hours; Seminar, two hours.-By Professor E. LANDAU: Algebraic numbers and ideals, four hours; The Galois theory of equations, two hours; Mathematical games and recreations, one hour; Seminar, two hours.-By Professor F. Bernstein: Theory of probabilities, three hours; Mathematics of insurance, two hours; Seminar, two hours.-By Dr. O. Toeplitz: Differential and integral calculus, with exercises, six hours; Theory of an infinite number of variables, two hours.-By Dr. A. HAAR: Celestial mechanics, two hours.-By Dr. E. Weys: Curves and surfaces, four hours; Theory of real variables, two hours; Exercises in analytic geometry, two hours.-By Dr. C. v. KÁRMÁN: Applications of the calculus of variations, three hours.-By Dr. R. Schimmach: The international commission on mathematical instruction, two hours.

The following university courses in mathematics are announced for the academic year 1912-1913. 
Columbia University. - By Professor C. J. Keyser: Modern theories in geometry, three hours; History and significance of central mathematical concepts, three hours. - By Professor T. S. Fiske: Introduction to the theory of functions of a real variable, three hours; Functions defined by linear differential equations, three hours. - By Professor F. N. Cole: Introduction to the theory of functions, three hours; Theory of plane curves, three hours. - By Professor James Maclay: Theory of numbers, three hours, first half-year; Differential equations, three hours, second half-year. - By Professor D. E. Sмгтн: History of mathematics, three hours. - By Professor EDWARD KASNER: Integral equations, two hours; Seminar in differential geometry, three hours. - By Professor W. B. Fite: Calculus of variations, three hours. - By Professor H. E. Hawkes: Modern higher algebra, three hours, second halfyear. - By Dr. H. W. REDDICK: Differential equations, three hours, first half-year. - By Dr. N. J. Lennes: Projective geometry, three hours.

The mathematical colloquium will meet at intervals of about two weeks.

Cornell University.-By Professor J. McMahon: Theory of probabilities, two hours; Vector analysis, two hours.-By Professor J. I. Hutchinson: Linear differential equations, two hours; Elliptic integrals, two hours (first term).-By Professor V. SNYDER: Analytic geometry of space, three hours (second term).-By Professor F. R. Sharpe: Introduction to mathematical physics, three hours.-By Professor W. B. CARver: Theory of equations, two hours; Descriptive geometry, three hours (first term).-By Professor A. Ranum: Differential geometry, two hours.-By Professor D. C. GILLESPIE: Principles of mechanics, three hours.-By Dr. C. F. CRAIG: Elementary differential equations, two hours.-By Dr. F. W. Owens: Projective geometry, three hours.-By Dr. J. V. McKelvey: Algebraic curves, three hours.-By Dr. L. L. Silverman: Advanced calculus, three hours.-By Dr. W. A. HuRwitz: Theory of functions of a complex variable, three hours.

THE following doctorates in mathematics were conferred by the French universities during the academic year 19101911: 
Paris, Doctorat d'Etat.

Caubet, P. "Etude des principales inégalités du mouvement de la lune qui dépendent de l'inclinaison."

Chazy, J. "Sur les équations différentielles du troisième ordre et d'ordre supérieur dont l'intégrale générale a ses points critiques fixes."

SIRE, J. "Sur les fonctions entières de deux variables d'ordre apparent total fini."

Chatelet, A. "Sur certains ensembles de tableaux et leur application à la théorie des nombres."

GaU, E. "Sur l'intégration des équations aux dérivées partielles du second ordre par la méthode de M. Darboux."

AnNycke, Th. "Contribution à l'étude thermomechanique des tiges et des plaques."

GaRNIER, R. "Sur les équations différentielles du troisième ordre dont l'intégrale générale est uniforme et sur une classe d'équations nouvelles d'ordre supérieur dont l'intégrale générale a ses points critiques fixes."

JANISZEWSKI, S. "Sur les continus irréductibles entre deux points."

VILLAT, H. "Sur la résistance des fluides."

\section{Doctorat d'Université.}

Gramont, A. de. "Essai d'aérodynamique du plan."

Lemaire, P. "Théorie des compas gyroscopiques."

Nancy, Doctorat d'Etat.

Arnoult, J. "Sur le mouvement d'un fil dans l'espace."

Lille, Doctorat d'Etat.

Barré, E. "Sur une classe de solutions des équations indéfinies de l'équilibre d'élasticité," et “Application de la géométrie cinématique à la théorie des surfaces engendrées par une courbe variable."

Professor G. B. Guccia, of the University of Palermo, has been elected a national member of the Royal Institute of Venice.

Professor G. Darboux, of the University of Paris, has been elected an honorary member of the Royal Irish academy. 
Dr. L. N. G. FILON has been appointed professor of applied mathematics at the University of London.

The mathematical prize of the Prince Jablonowski society for 1911 has been awarded to Professor EnNst Neumann.

Professor W. Kutta, of the technical high school at Aachen, has been appointed full professor of mathematics at the technical high school at Stuttgart.

Professor G. D. Birkhoff, of Princeton University, has accepted a call to an assistant professorship of mathematics at Harvard University.

$\mathrm{At}_{\mathrm{T}}$ the University of Missouri Dr. Louis Ingold has been promoted to an assistant professorship of mathematics.

At Columbia University Dr. L. P. Sicelofr has been promoted to an assistant professorship of mathematics. Mr. C. A. Fischer has been appointed instructor in mathematics.

Mr. R. W. Burgess has been appointed assistant in mathematics at Cornell University.

Ат Dartmouth College Dı. E. G. BiLl, of Purdue University, has been appointed assistant professor of mathematics. Drs. J. E. Rowe, of Haverford College, and F. M. Morgan, of Cornell University, have been appointed instructors in mathematics.

Professor J. Amsler-Laffon, inventor of the polar planimeter, died at Schaffhausen January 3, at the age of 89 years.

Dr. EmIL Lemorne, recipient of the Francoeur prize for several years, died at Paris, February 21, at the age of 72 years.

Professor Osborne Reynolds, of Owens College (now the University of Manchester) died February 21, at the age of 70 years. 